Research Article

\title{
Deformation and Failure Characteristics of the Roof in an Unsupported Area during Rapid Driving of Coal Roadway
}

\author{
Sen Yang $(\mathbb{D}$, Xinzhu Hua, Xiao Liu $(\mathbb{D}$, Enqian Wang, and Chen Li (i) \\ State Key Laboratory of Mining Response and Disaster Prevention and Control in Deep Coal Mines, \\ Anhui University of Science and Technology, Huainan 232001, Anhui, China \\ Correspondence should be addressed to Sen Yang; 1633234303@qq.com
}

Received 3 August 2021; Accepted 17 August 2021; Published 31 August 2021

Academic Editor: Xuepeng Zhang

Copyright (c) 2021 Sen Yang et al. This is an open access article distributed under the Creative Commons Attribution License, which permits unrestricted use, distribution, and reproduction in any medium, provided the original work is properly cited.

In order to study the deflection and failure characteristics of the goaf roof, a mechanical model of the goaf thin plate is established and the deflection expression of the goaf roof is obtained. The results show the following: (1) under the action of single factor, the roof deflection is more sensitive to the interaction of unsupported roof distance and load, but less sensitive to the support force. (2) The influence degree of each factor on the deflection of the thin plate in the unsupported top area is as follows: unsupported roof distance and load interaction > unsupported roof distance and supporting force > supporting force and load. (3) The roof bending deformation is slow when the unsupported roof distance is within $0-2.3 \mathrm{~m}$. When the vacant distance of the roof is more than $2.3 \mathrm{~m}$, the bending deformation of the roof is accelerated. Using FLAC3D numerical simulation software, the distribution of vertical stress and displacement under different space distances is analyzed and the reasonable space distance is $2.0 \mathrm{~m}$. Through the application of 150802 machine roadway in Liuzhuang coal mine, the driving speed of the coal roadway is improved and the monthly footage of coal roadway reaches $506 \mathrm{~m}$.

\section{Introduction}

In the recent years, with the development of roadway excavation and supporting technology and equipment, the speed of roadway excavation has been greatly improved. However, the efficiency and safety of roadway excavation are still low due to the limitation of geological conditions and various production processes of excavation $[1,2]$. The excavation and support affect the roadway driving speed at a time-consuming ratio of supporting and cutting of $3: 1$ [3]. Most coal mines often adopt cantilever roadheaders and single bolt drills for roadway excavation. The boring roadway operation involves frequent driving and exit of the roadheader, and workers moving the single bolt drill back and forth, which takes up a lot of tunneling time in a low roadway excavation efficiency $[4,5]$.

Much research was conducted to solve the low roadway excavation efficiency. Most research focused on the tunneling of the coal mine roadway integrated unit, continuous mining unit, and related auxiliary equipment in terms of rapid excavation technology and equipment. For example, the study in [6] proposed an integrated excavation and anchoring unit. According to the high-efficiency tunneling and the integrated supporting technology, the parallel tunneling operation line of tunneling, support, transportation, and dust removal has been constructed. After the 1980s, most coal mines in the United States adopted continuous tunneling machines, increasing the advancing speed of the tunneling face [7-9].

China first applied bolt supporting technology to coal mine roadways in 1956, which was listed as a scientific and technological development project during the "Eighth FiveYear Plan" period, enabling the development and application of coal road bolt support $[10,11]$. Under the premises of ensuring the safety of driving roadways, the efficiency of roadway excavation has been improved. For example, the study in [12] established a low-damage continuous beam control roof theory according to the roof deformation instability and support time-effect characteristics of coal roadways and developed a flexible anchoring technology 
that was not restricted by the height of the roadway. The study in [13] proposed that the high strength, high prestress, and high system rigidity were the core technology, and the large-spaced high-performance bolt support system was suitable for the rapid excavation of coal roadways. The Beijing Mining Research Institute of the Central Coal Research Institute has developed high prestress and strong bolt supporting technology, realizing the safe and efficient support of the bolt with the timely, high initial anchoring force and active support [14, 15]. The authors of $[16,17]$ proposed a combined support method combining two or more basic support methods, and selected appropriate support parameters for coupling, so as to control roadway deformation.

In terms of tunneling technology theory, scholars mainly focused on researching the cyclic footage, i.e., the distance between the unsupported roofs. The limited unsupported roof distance and the roof deformation and failure in the unsupported roof area were studied by establishing mechanical models such as roof beams and thin plates [18-20]. For example, the study in [21] established a beam structure model, analyzed the key factors affecting the roof stability of the unsupported roof area and the interaction relationships, and simulated a reasonable distance between the roofs. The study in [22] established a thin plate mechanical model, analyzed the roof stability of the unsupported roof area, and determined the limit unsupported roof distance during the tunnel driving. The study in [23] established a mechanical model for roof stability analysis and adopted the difference method to calculate the roof stress distribution law and the unsupported roof distance. According to the conditions of roof stability, the limited unsupported roof distance was obtained. Besides, the reasonable unsupported roof distance was determined using the surplus roof safety factor during roadway excavation.

The efficiency of roadway excavation is mainly reflected in the excavation and support. Realizing the parallel operation of excavation and support is the best way to improve the efficiency of roadway excavation. This paper analyzed the rules of roof deflection and subsidence under single factor and interaction through theoretical analysis and determined the size relationship of the factors that affected the roof stability. The reasonable void during the roadway excavation was determined by simulating the geological conditions of the 150802 machined roadway in the Liuzhuang Coal Mine. In terms of the supporting technology, the tunneling anchor was adopted to realize part of the bolt (cable) support. The field application showed that the fast excavation and fast support tunneling operation method greatly improved the tunneling efficiency of the roadway.

\section{Analysis of Roof Deformation in the Goaf Area}

2.1. A Mechanics Model of the Roof. After the roadway excavation, the stress of the surrounding rock changed from a three-dimensional stress state to a two-dimensional nonisostatic stress state, the bearing capacity of the rock mass at shallow decreased, and the surrounding rock gradually broke from shallow to deep [24-26]. Therefore, the destruction of the surrounding rock during roadway excavation could be regarded as the destruction of rock mass at shallow (direct roof). Figure 1 shows that the thickness of the direct roof is often much smaller than the width of the roadway for large-span roadways. The roof structure is similar to a plate, which can be analyzed using the plate theory $[27,28]$. For this reason, some assumptions are made for the direct roof of the goaf area and the support affected area: (1) the ratio of the thickness of the direct roof to the width of the roadway needs to meet the thin plate condition; (2) the two sides of the roadway and the coal body in front of the tunneling head provide sufficient support for the roof, while the supporting force of the bolt (cable) to the roof in the support area is small; and (3) the direct roof of the roadway is stable during the driving process. The direct roof of the unsupported roof area and the support affected area can be analyzed as a continuum, ignoring the discontinuous plastic failure.

According to the above assumptions, a thin plate model of the unsupported roof area is established with three sides fixed and one side simple supported and a direct roof support for the affected area, as shown in Figures 2 and 3 . Figure 3 shows that $a$ is the width of the roadway, $b$ is the unsupported length in the axial direction of the roof, $c$ is the length of the support in the axial direction of the roof, and $h$ is the thickness of the roof.

For a thin plate with three sides fixed and one side supported, the boundary conditions are

$$
\left\{\begin{array}{l}
\omega_{x=0}=0,\left(\frac{\partial \omega}{\partial x}\right)_{x=0}=0, \\
\omega_{x=a}=0,\left(\frac{\partial \omega}{\partial x}\right)_{x=a}=0, \\
\omega_{\mathrm{y}=0}=0,\left(\frac{\partial \omega}{\partial y}\right)_{y=0}=0, \\
\omega_{\mathrm{y}=b+c}=0,\left(\frac{\partial^{2} \omega}{\partial y^{2}}\right)_{y=b+c}=0 .
\end{array}\right.
$$

According to the small deflection bending theory of thin plate in elasticity and the superposition principle [29-31], the mechanical model of the roof can be divided into two parts to calculate separately, and then the results of the two parts are superposed:

Part 1: the thin plate only acts on a uniformly distributed load $q_{0}$, and the deflection $\omega$ of the thin plate is set by the expression of the heavy triangular series,

$$
\omega=\sum_{j=1}^{\infty} \sum_{k=1}^{\infty} A_{m n} \sin \frac{j \pi x}{a} \sin \frac{k \pi y}{b+c} .
$$

According to the differential equation of the elastic surface of the thin plate: $D \nabla^{4} \omega=q_{0}$, we get 


$$
A_{m n}=\frac{16 q_{0}}{\pi^{6} D j k\left(\left(j^{2} / a^{2}\right)+\left(k^{2} /(b+c)^{2}\right)\right)^{2}} \quad(j=1,3,5 ; k=1,3,5) .
$$

Substituting into equation (2), the expression for the deflection of the thin plate is

$$
\omega_{1}=\frac{16 q_{0}}{\pi^{6} D} \sum_{j=1,3,5 \ldots}^{\infty} \sum_{k=1,3,5 \ldots}^{\infty} \frac{\sin (j \pi x / a) \sin (k \pi y / b+c)}{j k\left(\left(j^{2} / a^{2}\right)+\left(k^{2} /(b+c)^{2}\right)\right)^{2}} .
$$

Part 2: the thin plate is only affected by the upward bolt support force $\mathrm{F}$ in the supporting area. The upward distributed load on the thin plate is $(F / \mathrm{d} x \mathrm{~d} y)(\mathrm{m}, n$ are the number of bolts in the $x$ and $y$ directions of the thin inner plate of the support, respectively). Therefore, except for the bolt action point $(\varepsilon, \eta)$, the distributed load of the thin plate is 0 . Similarly, the deflection of the thin plate is supposed as a trigonometric series (equation (2)), which can be substituted into the thin plate balance differential equation to obtain

$$
A_{m n}=\frac{4 F}{\pi^{4} D a(b+c)\left(\left(j^{2} / a^{2}\right)+\left(k^{2} /(b+c)^{2}\right)\right)^{2}} \sin \frac{j \pi \xi}{a} \sin \frac{k \pi \eta}{b+c}
$$

Substituting into equation (2), the deflection expression of the thin plate is obtained as

$$
\omega_{2}=\frac{4 F}{\pi^{4} a(b+c) D} \sum_{j=1,3,5 \ldots}^{\infty} \sum_{k=1,3,5 \ldots}^{\infty} \frac{\sin (j \pi \xi / a) \sin (k \pi \eta / b+c)}{\left(\left(j^{2} / a^{2}\right)+\left(k^{2} /(b+c)^{2}\right)\right)^{2}} \sin \frac{j \pi x}{a} \sin \frac{k \pi y}{b+c} .
$$

Therefore, the deflection of the thin plate after superposition is expressed as $\omega=\omega_{1}-\omega_{2}$, which is

$$
\omega=\frac{16 q_{0}}{\pi^{6} D} \sum_{j=1,3,5 \ldots}^{\infty} \sum_{k=1,3,5 \ldots}^{\infty} \frac{\sin (j \pi x / a) \sin (k \pi y / b+c)}{\left(\left(j^{2} / a^{2}\right)+\left(k^{2} /(b+c)^{2}\right)\right)^{2}} \cdot\left(\sum_{j=1,3,5 \ldots}^{\infty} \sum_{k=1,3,5 \ldots}^{\infty}\left(\frac{1}{j k}-\frac{\pi^{2} F}{4 q_{0} a(b+c)} \sin \frac{j \pi \xi}{a} \sin \frac{k \pi \eta}{b+c}\right)\right) .
$$

In formula (7), $D=\left(E h^{3} / 12\left(1-\mu^{2}\right)\right)$ and substituting formula (7) into the boundary mentioned above, conditions of the thin plate are all satisfied. When calculating the deflection of the thin plate, since the deflection of the thin plate is a heavy triangular series, the convergence is fast. Therefore, the first three terms of the heavy triangular series can be selected to meet the accuracy of the thin plate deflection.

\subsection{The Law of Roof Deformation under Different Influencing} Factors. According to formula (7), the roof deformation under different factors was analyzed. For the convenience of calculation, the roof length $c$, the roof width a, the roof thickness $h$, and Poisson's ratio $\mu$ of the support area were selected as $4.0 \mathrm{~m}, 5.0 \mathrm{~m}, 1.5 \mathrm{~m}$, and 0.4 , respectively. The modulus of elasticity is $500 \mathrm{MPa}$.

2.2.1. Supporting Force $F$ in the Supporting Area. Under the conditions of $q_{0}=10 \mathrm{MPa}, b=4.0 \mathrm{~m}$, Figure 4 shows the flexural deformation of the top plate when the supporting force $\mathrm{F}$ is $40 \mathrm{kN}, 80 \mathrm{kN}$, and $120 \mathrm{kN}$, respectively. The results show that with the increase in the bolt support force, the roof deflection and sinking do not change much, and the peak position of the roof deflection is close to the heading direction of the tunneling in a small range.
2.2.2. A Load $q_{0}$ of Overlying Strata on the Direct Roof. Under the conditions of $F=80_{\mathrm{kN}}$ and $b=4.0 \mathrm{~m}$, Figure 5 shows the flexural deformation of the top plate when the load $q_{0}$ is selected as $5 \mathrm{MPa}, 10 \mathrm{MPa}$, and $15 \mathrm{MPa}$, respectively. The results show that the maximum deflection appears in the goaf area due to the absence of support. As the load of the overlying strata increases, the deflection and deformation of the roof increases, with the maximum deflection occurring at a position with equal head-on distance from the tunneling.

2.3. Unsupported Roof Distance $b$. Under the conditions of $q_{0}=10 \mathrm{MPa}$ and $F=80_{\mathrm{kN}}$, Figure 6 shows the flexural deformation of the top plate when the unsupported roof distance $b$ is selected as $2.0 \mathrm{~m}, 4.0 \mathrm{~m}$, and $6.0 \mathrm{~m}$, respectively. It can be seen from Figure 6 that when the unsupported roof distance is small, the peak deflection of the roof appears at the junction of the unsupported roof area and the support area because the tunneling head-on mainly controls the roof of the unsupported roof area. With the increase in the distance of the roof, the deflection and deformation of the roof in the roof area increase, and the peak deflection gradually shifts to the right, which in turn drives the roof in the support area to flex further and sink, leading to the decreased roof stability.

Figures 4-6 show that the deflection deformation of the roadway roof is more sensitive to the unsupported roof 


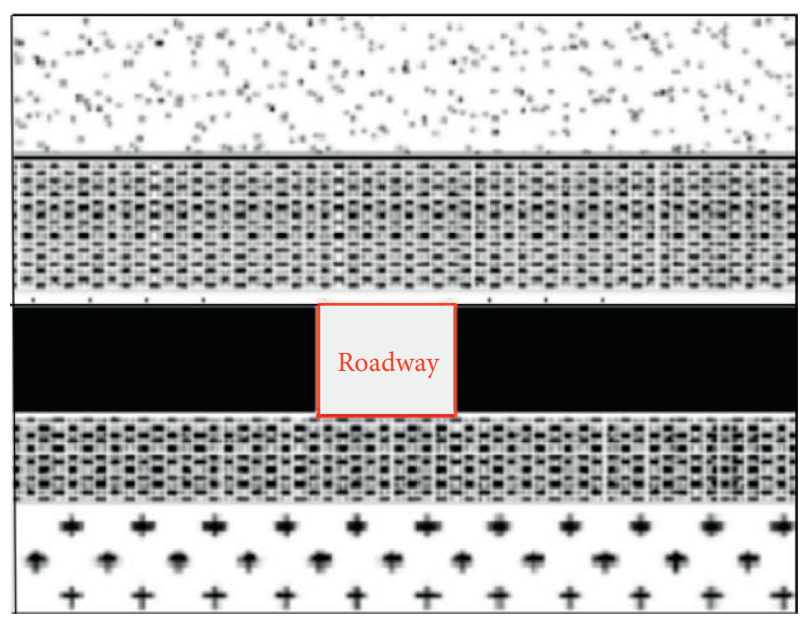

FIGURE 1: Schematic diagram of rock distribution of the large-span roadway.

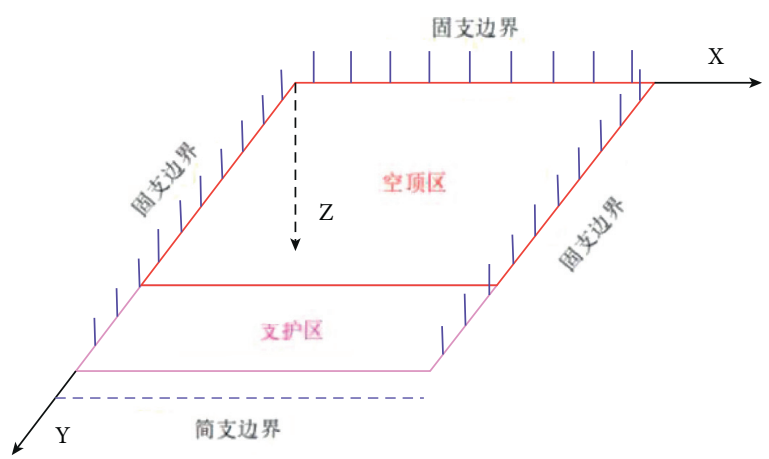

Figure 2: The boundary state of the roadway roof.

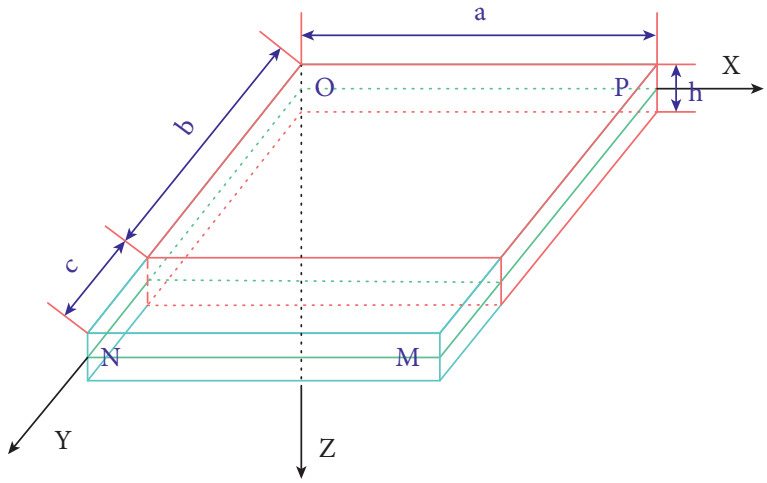

Figure 3: Mechanical model of the roadway roof.

distance and the load interaction and less sensitive to the supporting force. If the load of the overlying rock layer has been determined, the distance of the unsupported roof and the supporting force should be determined reasonably to ensure the stability of the roof during the roadway excavation.

To further analyze the deflection and deformation of the roof under the interaction of the distance between the unsupported roof and the supporting force, and the overburden load, the unsupported roof distance and the

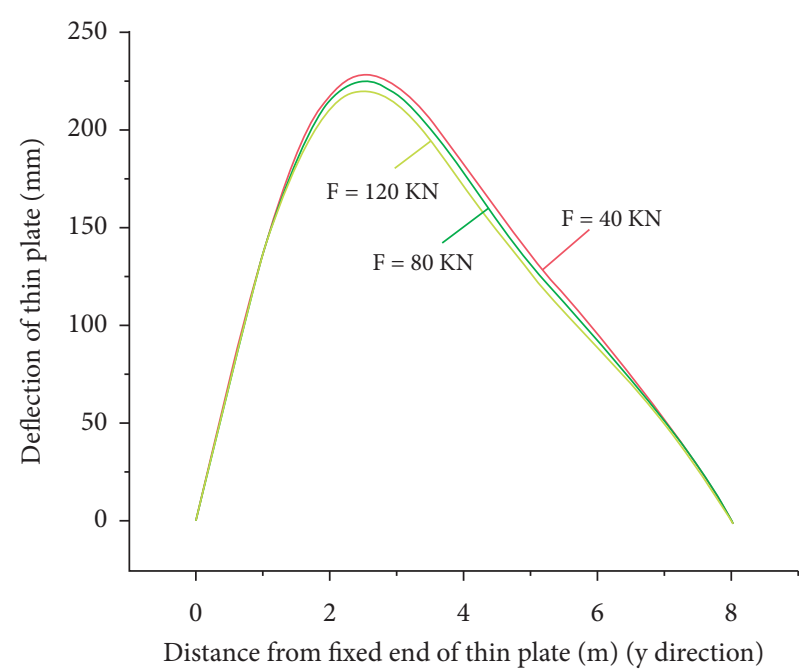

Figure 4: Curves of roof deflection under different supporting forces.

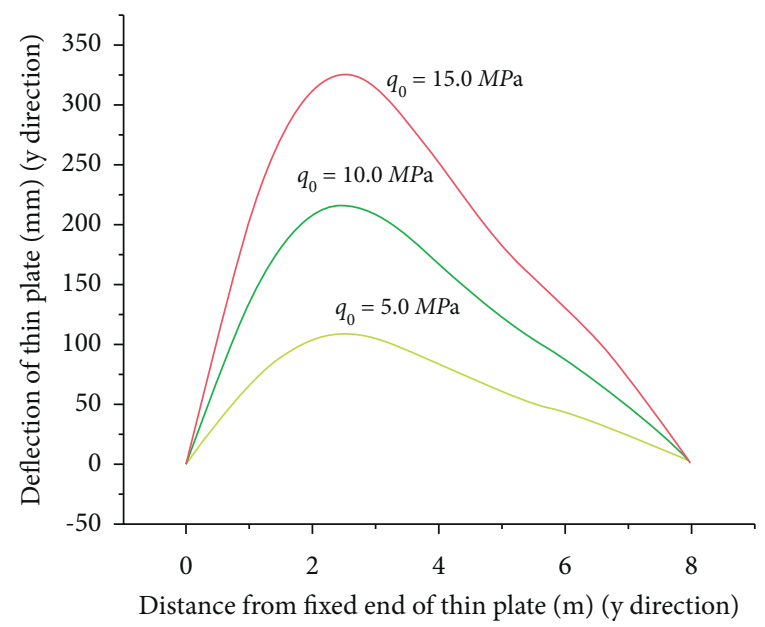

Figure 5: Variation curve of roof deflection under different overlying strata loads.

supporting force, the unsupported roof distance and the overburden load and support are obtained according to formula (7). The response surface of the roof deflection and deformation under the supporting force and load interaction is shown in Figures 7-9 .

Figures 7-9 show that the degree of influence on the deflection and deformation of the roof in the descending order is as follows: unsupported roof distance and load interaction $>$ unsupported roof distance and supporting force interaction $>$ supporting force and load interaction. When the unsupported roof distance is in the range of $0 \sim 2.3 \mathrm{~m}$, the top plate flexural deformation is slow. When the unsupported roof distance exceeds $2.3 \mathrm{~m}$, the top plate flexural deformation accelerates. When the supporting force of the roadway roof exceeds $50 \mathrm{kN}$, the deflection and deformation of the roof decrease quickly. When the unsupported roof distance exceeds $2.3 \mathrm{~m}$ and the supporting force is less than $50 \mathrm{kN}$, the deflection and sinking speed of the roof are fast, leading to the increased control difficulty. 


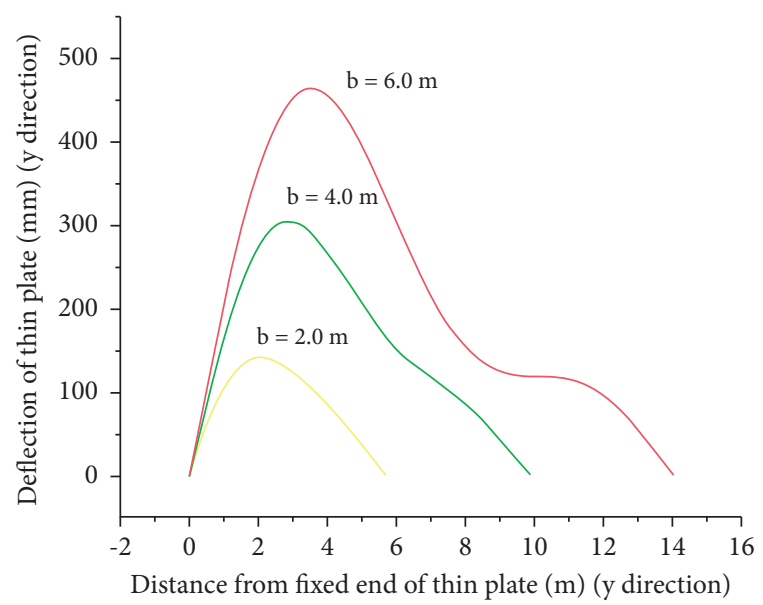

Figure 6: The change curve of roof deflection at different unsupported roof distances.

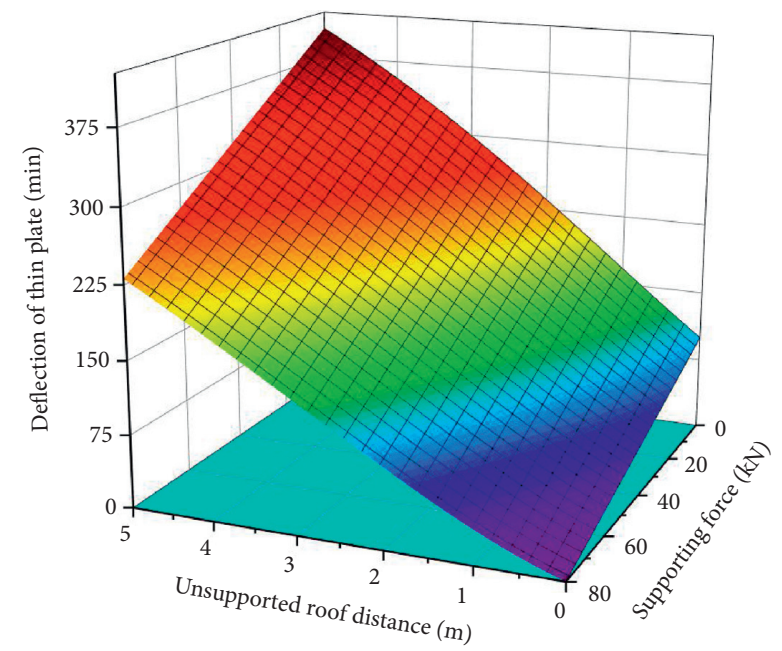

FIgURE 7: The response surface of roof deflection and deformation under unsupported roof distance and supporting force.

\section{Simulation Analysis of Roof Stability in the Goaf Roof Area of the Driving Face}

3.1. Establishment of the Numerical Model. According to the geological conditions of the 150802 belt along with Liuzhuang Coal Mine, a numerical calculation model is established, as shown in Figure 10. The mining coal seam is 8 seams, the floor elevation is about $-618.43 \mathrm{~m} \sim-567.44 \mathrm{~m}$, the mining strike length is $1610.0 \mathrm{~m}$, the inclination angle of the coal seam is $7^{\circ}-12^{\circ}$, and the average inclination angle is $9^{\circ}$, which can be approximated as horizontal mining. The model size is $X \times Y \times Z=80 \mathrm{~m} \times 60 \mathrm{~m} \times 40 \mathrm{~m}$. The upper boundary of the model is loaded with overlying strata load, and the bottom of the model and the other four sides are set with displacement boundaries. The section size of the roadway is $5.8 \times 4.2 \mathrm{~m}$ (width $\times$ height). The Mohr-Coulomb yield criterion is used in the calculation of the numerical model. The mechanical parameters of coal and rock mass are shown in Table 1.
The physical and mechanical parameters of the roof and floor of the roadway are shown in Table 1.

The bolt-net-cable support form is adopted in the roadway excavation. According to the bolt (cable) support parameters of Liuzhuang Coal Mine, left-hand threaded metal strong bolts are used for the bolts, and the row spacing between bolts is selected to be $900 \times 900 \mathrm{~mm}$, and the anchor preload must be greater than $50 \mathrm{kN}$. The anchor cable is made of prestressed steel strands with a diameter of $21.8 \mathrm{~mm}$ and a length of $9.2 \mathrm{~m}$. The row spacing is $1600 \times 1200 \mathrm{~mm}$, and the anchor cable pretightening force is not less than $120 \mathrm{kN}$. The tunnel section support parameters are shown in Figure 11.

3.2. Influence of Unsupported Roof Distance on the Roadway Roof Stability. In roadway excavation, the roof stability of the goaf area is controlled by the roof of the rear support area and the front coal wall. When the distance of the goaf roof is small, the coal wall in front of the roadway is important in controlling the roof stability of the goaf area. The supporting effect of the roof of the area is not obvious. When the distance of the unsupported roof is large, the roof of the unsupported roof area is controlled by the roof of the rear support area and the front coal wall. The support strength of the roof of the rear support area is greater than the support strength of the front coal wall. The deflection of the roof in the unsupported roof is distorted, showing that the axial roof in the unsupported roof area has a maximum value, which will increase the tensile stress of the roof. When the tensile stress reaches the tensile strength of the tensile roof rock mass, the roof will break and collapse.

To analyze the influence of the unsupported roof distance on the axial roof stability of the roadway, the vertical stress and vertical displacement of the axial roof of the roadway were analyzed using FLAC3D numerical simulation software with the unsupported roof distances at $1.0 \mathrm{~m}$, $2.0 \mathrm{~m}$, and $3.0 \mathrm{~m}$, respectively. The characteristics of distribution evolution are given below.

\subsection{Influence of Unsupported Roof Distance on the Vertical} Stress of the Surrounding Rock of the Roadway. Figure 12 shows the vertical stress distribution cloud diagram of the surrounding rock of the roadway when the distance of the unsupported roof is selected as $1 \mathrm{~m}, 2 \mathrm{~m}$, and $3 \mathrm{~m}$. The results show that there is an obvious end effect in the vertical stress distribution of the surrounding rock of the roadway after the excavation, leading to the large rock mass stress gradient near the tunneling face and a leading stress peak in front of the tunneling face. With the increase in the unsupported roof distance, the gradient change in roof rock mass stress is extremely small, and the peak stress decreases from $16.09 \mathrm{M} \mathrm{Pa}$ to 16.06 $\mathrm{MPa}$, less than $2 \%$. Therefore, the unsupported roof distance change does not affect the vertical stress distribution of the roadway roof. However, the change in the unsupported roof distance greatly influences the vertical stress of the roadway ledge. When the unsupported roof distance is increased from $1.0 \mathrm{~m}$ to $3.0 \mathrm{~m}$, the peak high support stress of the ledge increases from 16.406 $\mathrm{MPa}$ to $16.624 \mathrm{MPa}$, an increase of nearly 


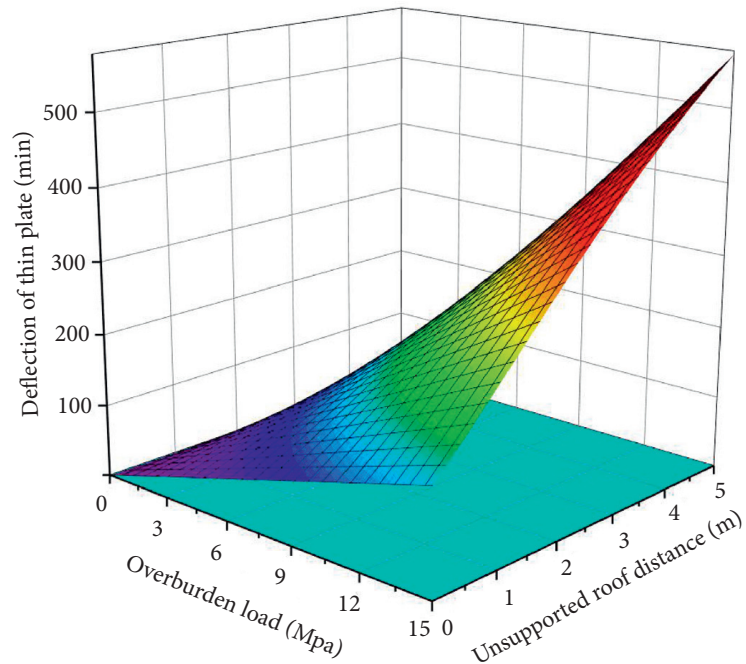

FIGURE 8: The response surface of roof deflection and deformation under unsupported roof distance and load.

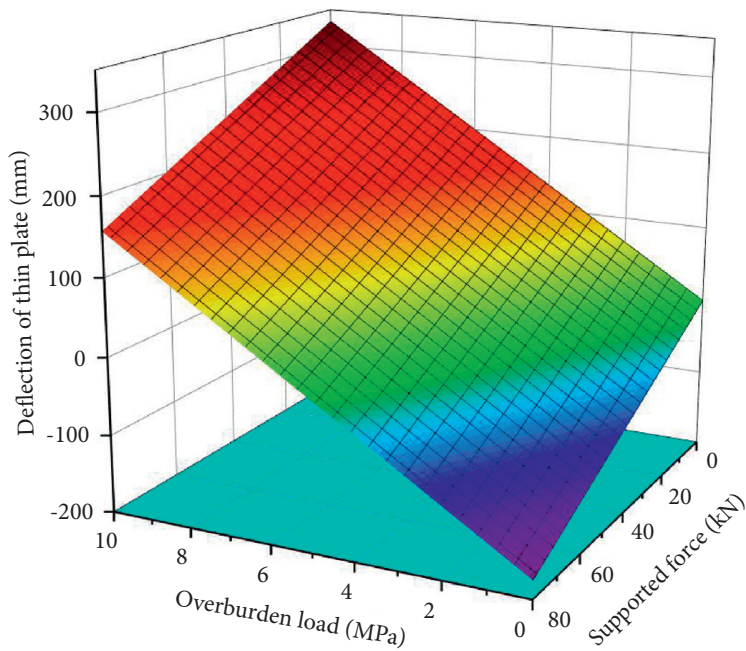

FIGURE 9: The response surface of roof deflection and deformation under supporting force and load.

$2 \%$. However, due to the small space-top distance, the distribution of the high-supporting stress area of the siding does not change significantly. When the space-top distance increases from $2.0 \mathrm{~m}$ to $3.0 \mathrm{~m}$, the distribution of the high-supporting stress area of the siding increases slightly, and the change in the speed of the peak stress increases, as shown in Figure 13.

In order to analyze the radial and vertical stress distribution on different sections of the roadway, three types of roadway radial sections are selected: support area $(15.0 \mathrm{~m}$ behind the heading), unsupported roof area ( $2.0 \mathrm{~m}$ behind the heading), and stress reduction ( $10.0 \mathrm{~m}$ in front of the heading), as shown in Figure 14. Figure 13 shows that, after the excavation, the magnitude and distribution range of the high stress in the shallow rock mass in the upper part of the roadway support area is large, and the magnitude and distribution range of the high stress of the rock mass in the upper part of the hollow roof area is small. The stress distribution in the range is consistent. The stress distribution in the front of the tunnel is increased due to the disturbance from tunneling.
3.4. Influence of Unsupported Roof Distance on the Vertical Displacement of the Roof. Figure 15 shows the axial roof vertical displacement of the roadway with the unsupported roof distance at $1 \mathrm{~m}, 2 \mathrm{~m}$, and $3 \mathrm{~m}$. The results show that with the increase in the unsupported roof distance, the roof deformation in the unsupported roof area increases, leading to a further increase in the roof deformation in the support area behind the roadway. When the unsupported roof distance is in the range of $0-2.0 \mathrm{~m}$, the roof does not exhibit obvious bending and sinking phenomenon, and the subsidence is lower than the roof subsidence of the last row of supports of the roadway. When the unsupported roof distance reaches $3.0 \mathrm{~m}$, the inner roof exhibits obvious bending and sinking phenomenon, the maximum value appears at a position of $1.0 \mathrm{~m}$ from the tunnel head, and the sinking amount is $11.5 \%$ larger than that of the last row of supports of the roadway. Therefore, to ensure the safe and efficient production of the excavation roadway, the unsupported roof distance is selected to be $2.0 \mathrm{~m}$. 


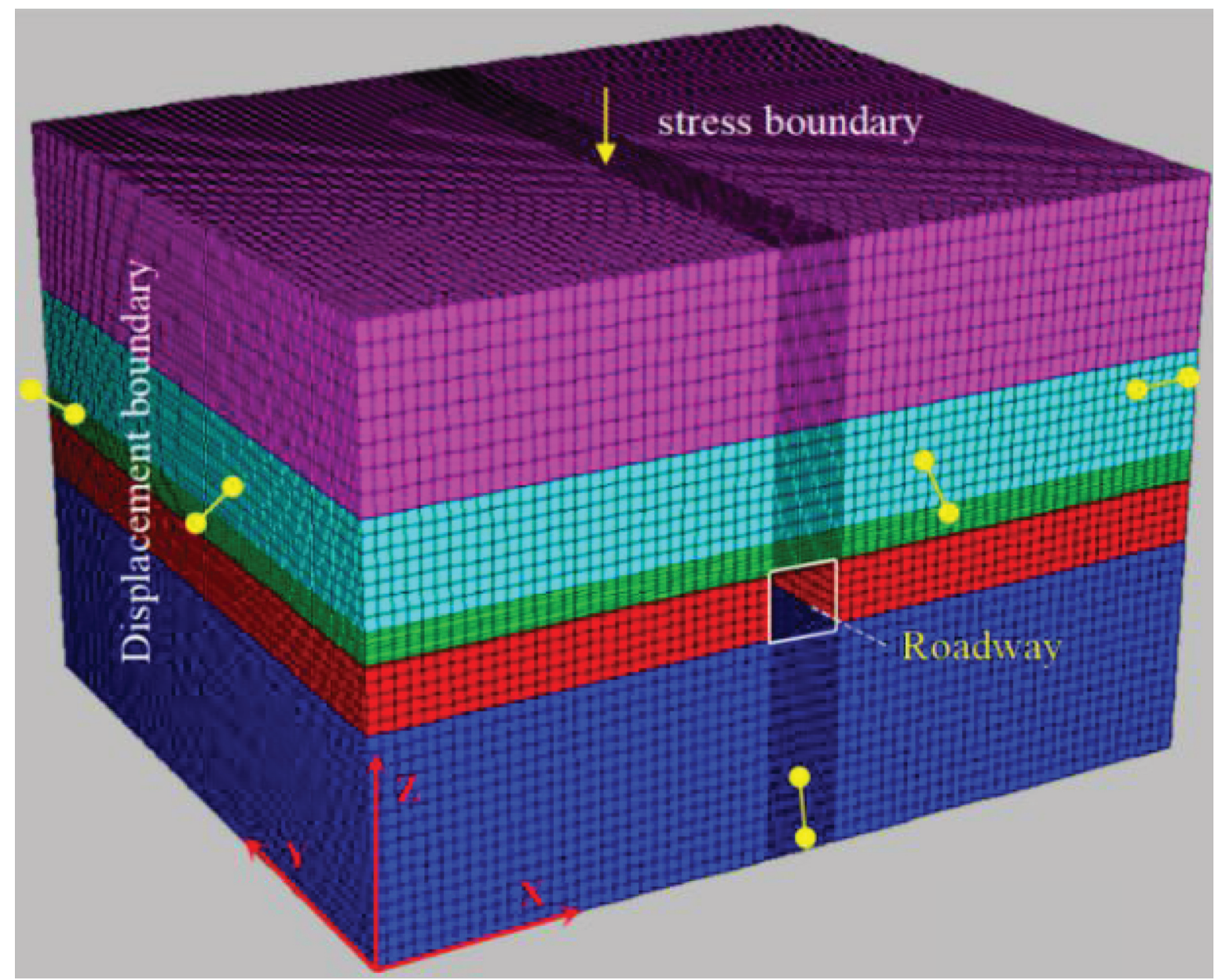

FIGURE 10: Numerical calculation model.

TABle 1: Mechanical parameters of the coal roof and floor.

\begin{tabular}{|c|c|c|c|c|c|c|c|}
\hline No. & Lithology & Thickness (m) & $\begin{array}{l}\text { Density } \\
\left(\mathrm{kg} / \mathrm{m}^{3}\right) \\
\end{array}$ & $\begin{array}{l}\text { Bulk modulus } \\
(\mathrm{GPa})\end{array}$ & $\begin{array}{l}\text { Shear modulus } \\
\qquad(\mathrm{GPa})\end{array}$ & $\begin{array}{l}\text { Internal friction angle } \\
\left({ }^{\circ}\right)\end{array}$ & Cohesion (MPa) \\
\hline 5 & Fine sandstone & 7.74 & 2700 & 8.35 & 7.1 & 35 & 3.75 \\
\hline 4 & $\begin{array}{l}\text { Sandy } \\
\text { mudstone }\end{array}$ & 1.15 & 2500 & 5.2 & 3.4 & 30 & 2.05 \\
\hline 3 & 8 coal & 3.54 & 1400 & 1.5 & 0.63 & 23 & 0.72 \\
\hline 2 & Mudstone & 3.01 & 2400 & 3.58 & 1.53 & 23 & 1.17 \\
\hline 1 & Siltstone & 4.35 & 2500 & 6.5 & 6.74 & 32 & 3.15 \\
\hline
\end{tabular}

\section{Field Test}

4.1. Geological Overview. The 150802 machine lane is generally a monoclinic structure, with the belt going uphill in the 1508 mining area in the east, 150802 working face in the west, 150804 working face in the south, 150802 working face in the north, and 151101 working face and 151102 working face goaf up there. Figure 16 shows the 150802 machine lane layout.

4.2. Roadway Construction Technology and Process. The 150802 roadway adopted the complete set of equipment of the rapid excavation system developed by the Taiyuan Coal
Research Institute for excavations, as shown in Figure 17. The specific construction process is as follows: anchor-net support process for roadheader construction: safety inspection (roof, gas, engineering quality, etc.) $\longrightarrow$ roadheader excavation and shipment $\longrightarrow$ safety inspection $\longrightarrow$ net hanging, hanging $\mathrm{H}$ steel belt $\longrightarrow$ temporary support $\longrightarrow$ construction of Gable antipatch protection net $\longrightarrow$ roofing anchor rod $\longrightarrow$ brushing for shipment $\longrightarrow$ hanging net and hitting two anchor rods (safety inspection runs through the whole process of operation).

The 150802 roadway adopts the anchor-net-cable support form during tunneling. When the bolt is installed, each bolt hole requires one roll of MSK2850 and one roll of MSZ2850 anchoring agent. To ensure the 


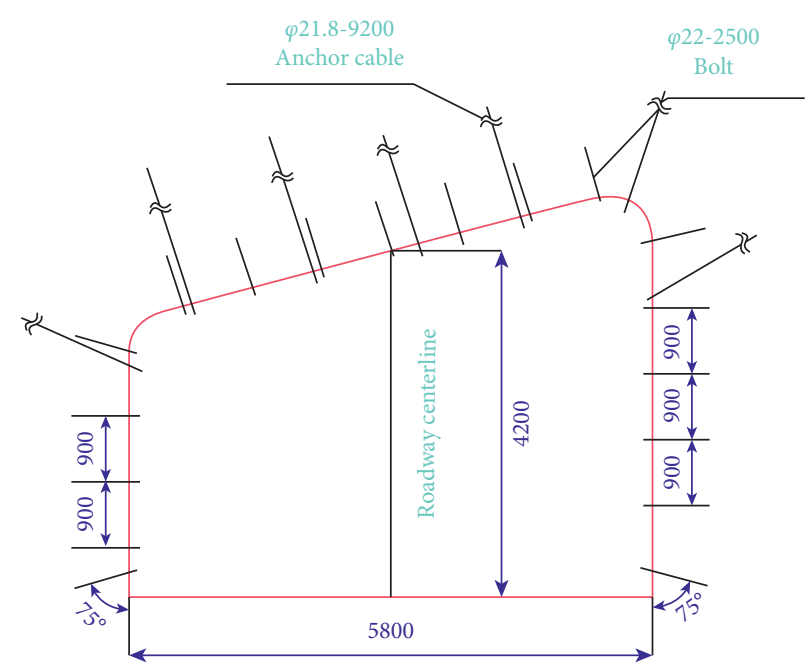

FIGURE 11: Roadway section support layout.
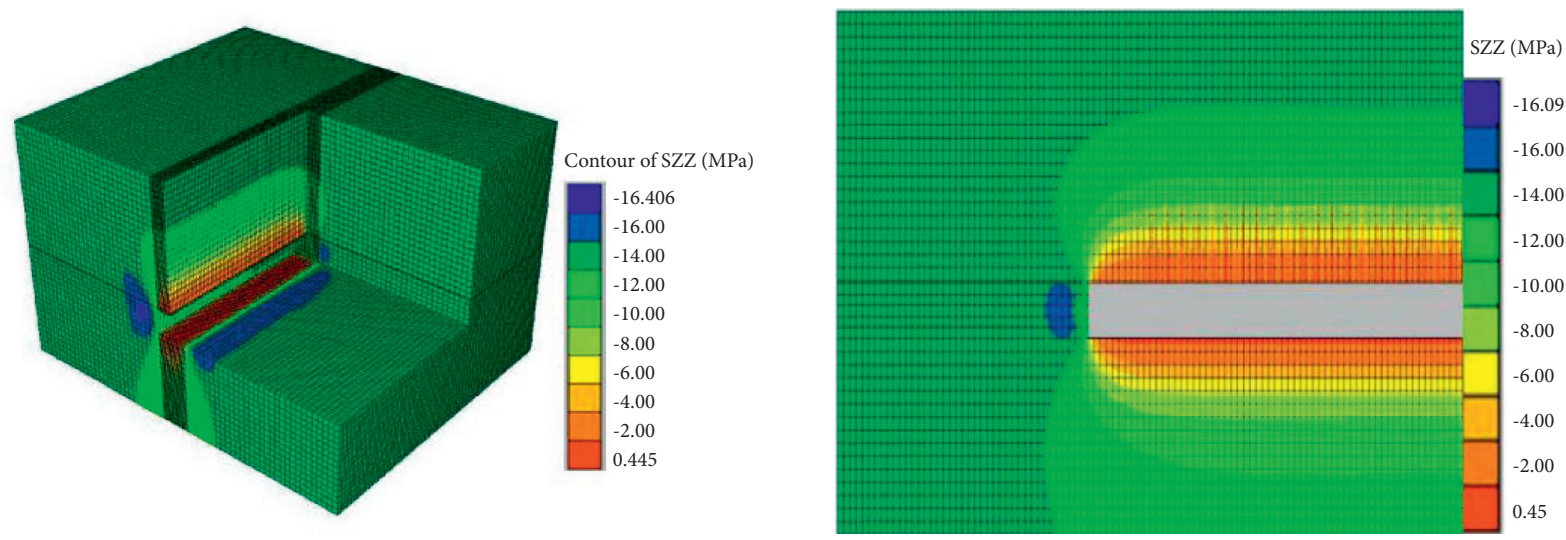

(a)
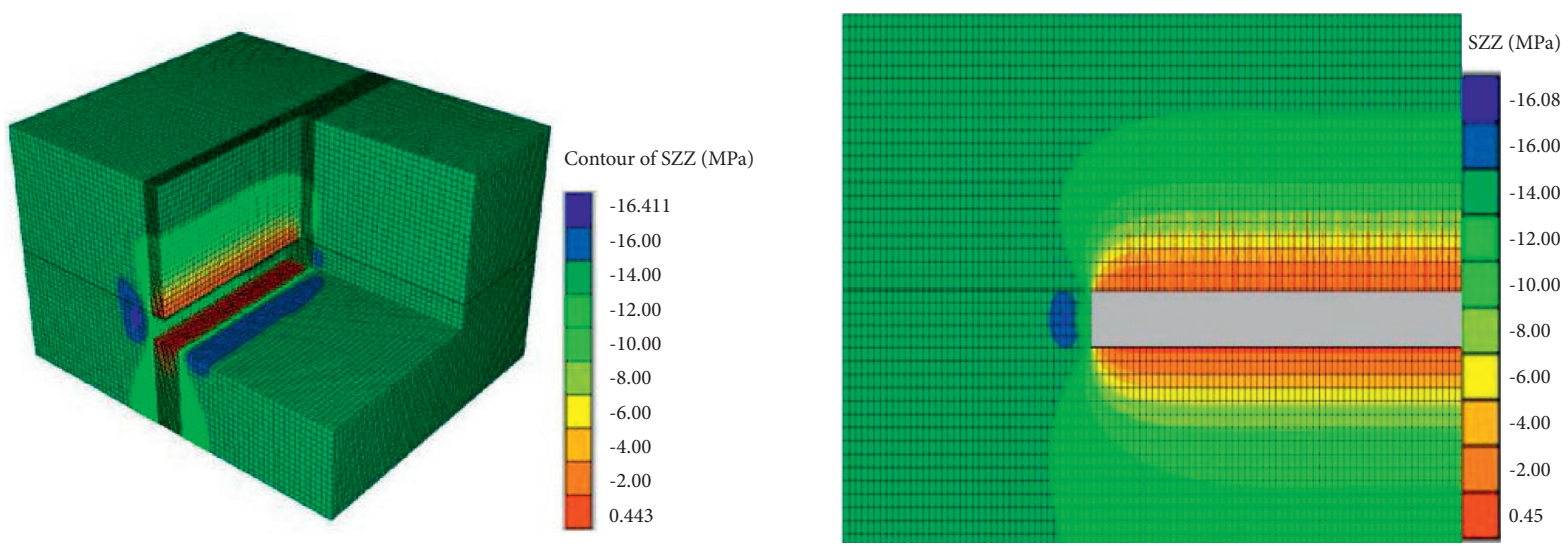

(b)

FIgUre 12: Continued. 

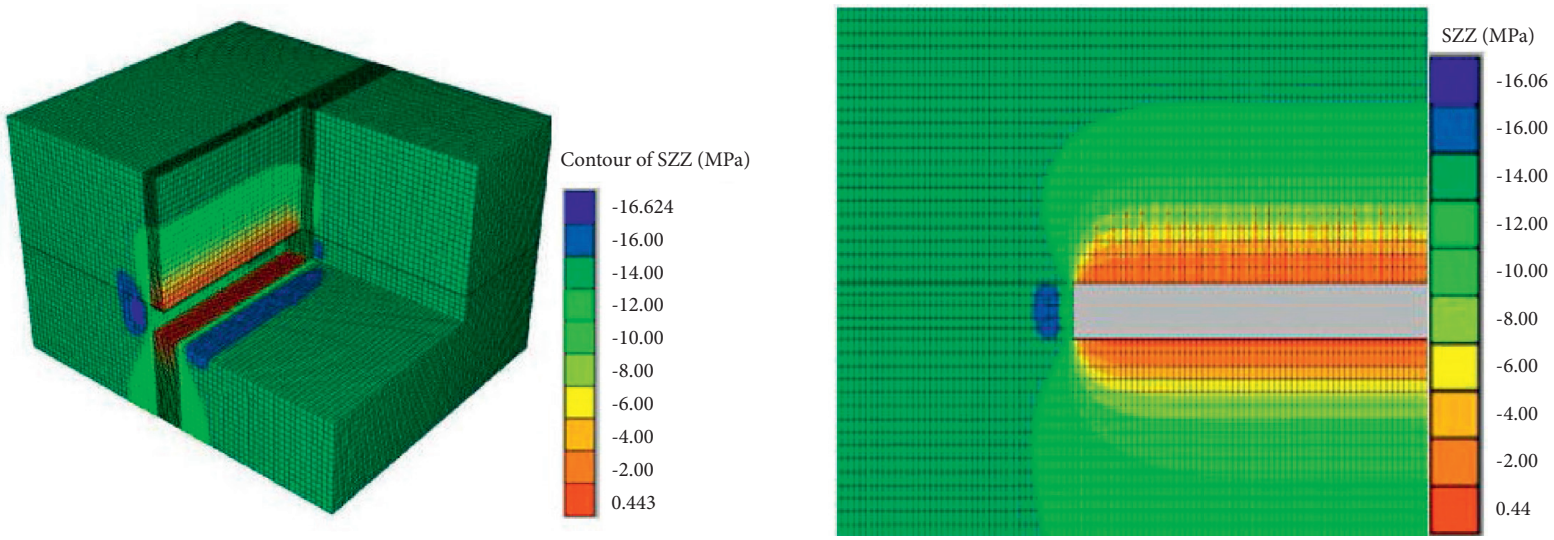

(c)

FIGURE 12: Vertical stress cloud diagram of surrounding rock of roadway under different unsupported roof distances: when the unsupported roof distances is (a) $1.0 \mathrm{~m},(\mathrm{~b}) 2.0 \mathrm{~m}$, and (c) $3.0 \mathrm{~m}$.

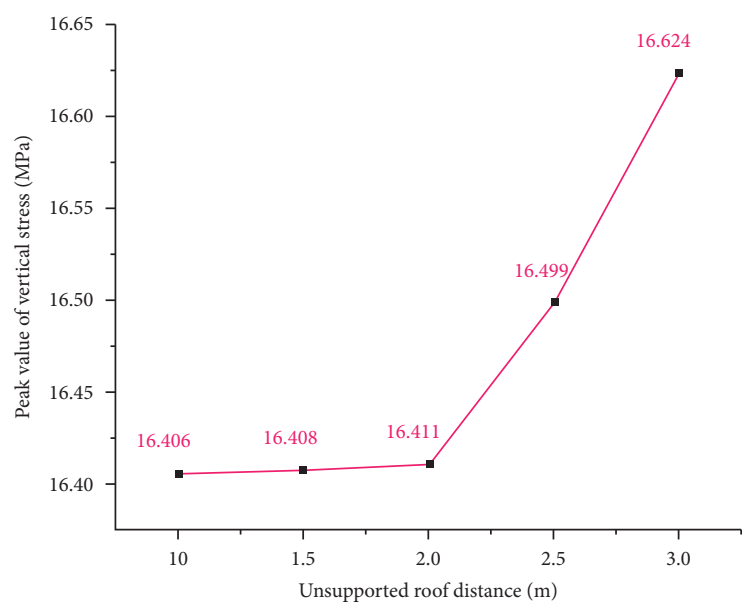

FigURE 13: The influence of the change in the unsupported roof distance on the vertical stress peak value of the upper part.

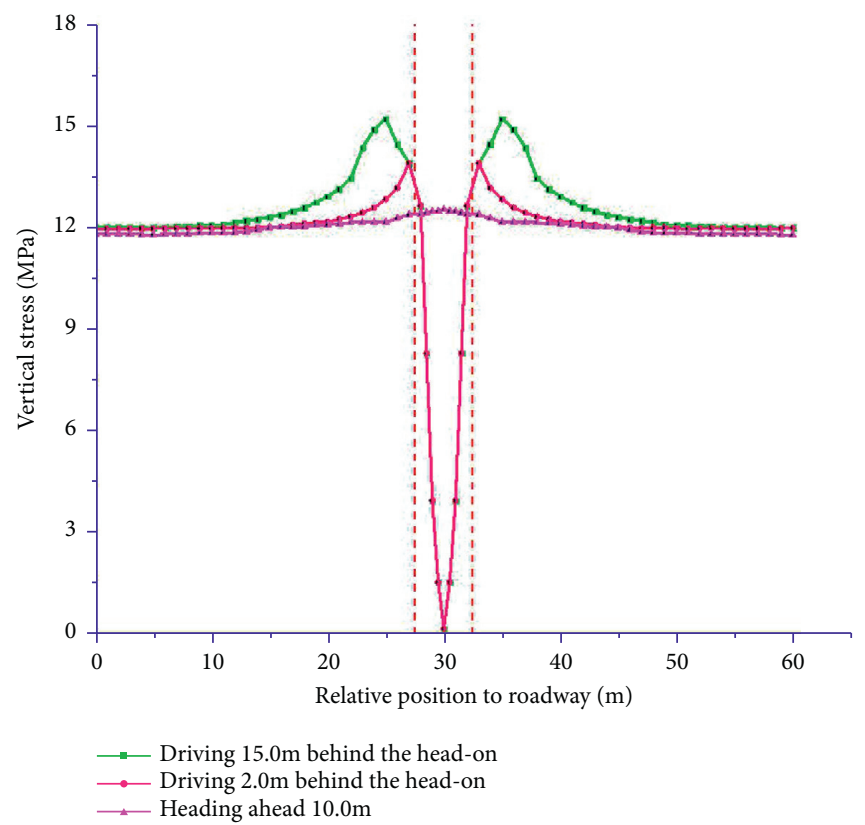

FIGURE 14: Radial and vertical stress distribution at different sections of the roadway. 


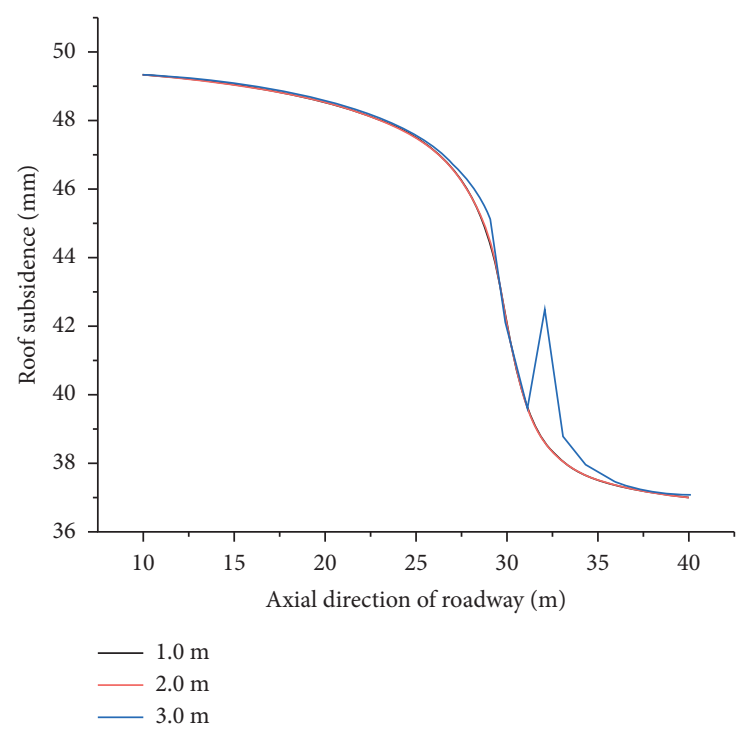

Figure 15: The deformation curve of the roof under the three kinds of unsupported roof distances.

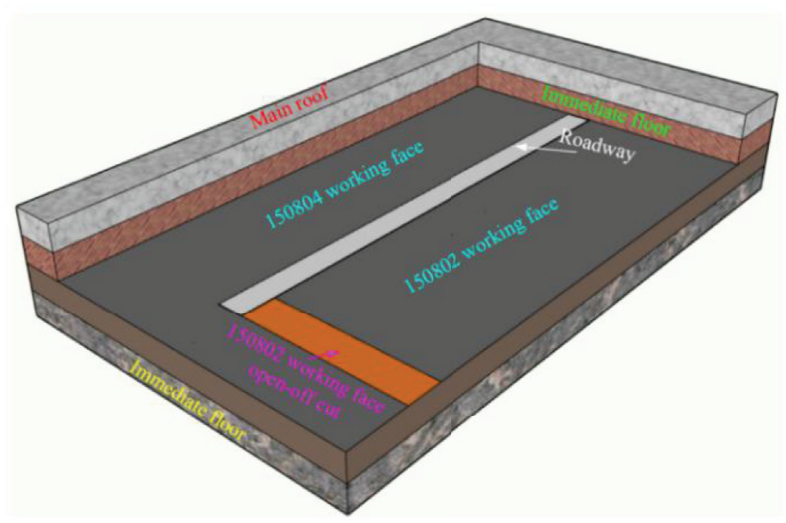

Figure 16: Adhesive tape arrangement on the 150802 working face.

quality of the bolt support, the medium torque is not less than $300 \mathrm{~N} \cdot \mathrm{m}$, the anchoring force is not less than $100 \mathrm{kN}$, the torque is not less than $200 \mathrm{~N}$ m when installing in the coal seam, and the anchoring force is not less than $50 \mathrm{kN}$. When installing the anchor cable, 1 roll of MSK2850 and 2 rolls of MSZ2850 resin anchoring agents for each anchor cable is used. The anchor end of the anchor cable should be anchored in the hard solid rock layer, and the pretightening force of the anchor cable should not be less than $120 \mathrm{kN} /$ piece. In the process of construction anchoring, to increase the speed of the construction support, part of the construction work is carried out by using the on-board hydraulic rig of the tunneling anchorage part (Figure 18), which has the faster drilling speed, lower noise, and better construction environment compared with the manual hand-held pneumatic rig.

4.3. Mine Pressure Observation and Effect. The unsupported roof distance of $2.0 \mathrm{~m}$ is applied to the 150802 belt along with the groove. To analyze the convergence and deformation of the roadway during tunneling, the "crosspoint method" is used for monitoring. The measuring station was arranged at $1100 \mathrm{~m}$ from the starting point of the roadway. After the station arrangement is completed, the initial monitoring of the roadway convergence and deformation is carried out at the position of the measuring station and then every $24 \mathrm{~h}$. The monitoring results are shown in Figure 19, showing that when the roadway deformation in the rear support zone reaches a stable stage during the 150802 belt tunneling, the maximum relative movement of the roof and floor is $120 \mathrm{~mm}$, and the maximum relative movement of the two sides is $105 \mathrm{~mm}$. The overall roadway is relatively stable, as shown in Figure 20. Before process optimization, the average monthly footage of the roadway was $311 \mathrm{~m}$. After the optimization, the monthly footage of the roadway tunneling reaches $506 \mathrm{~m}$, and the tunneling speed is increased by $62.7 \%$, realizing the safety and efficiency of coal mine tunneling, as shown in Figure 21. 


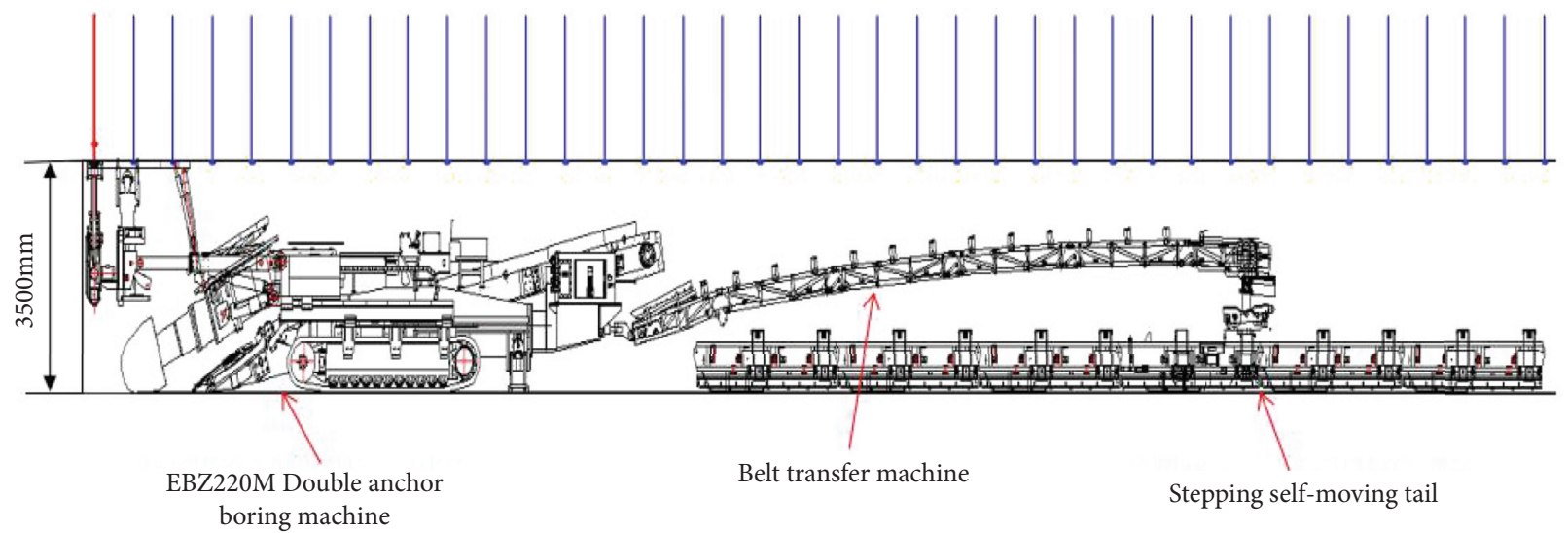

FIGURE 17: Equipment matching for the rapid excavation system.

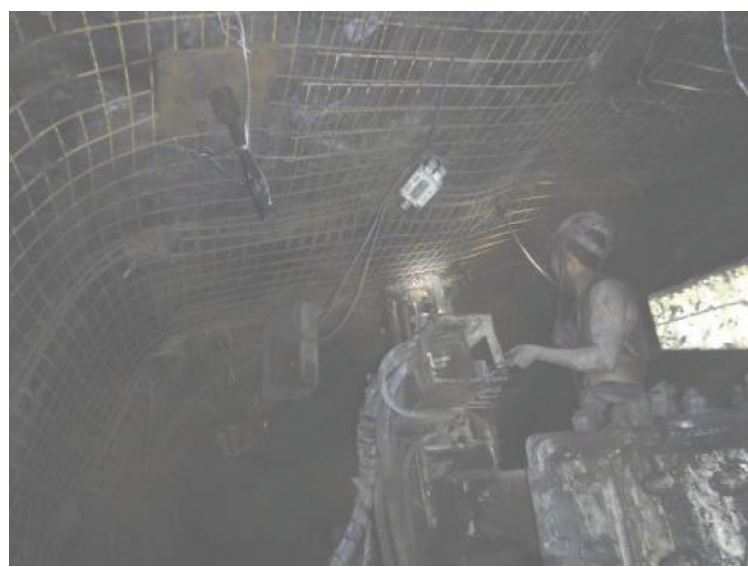

(a)

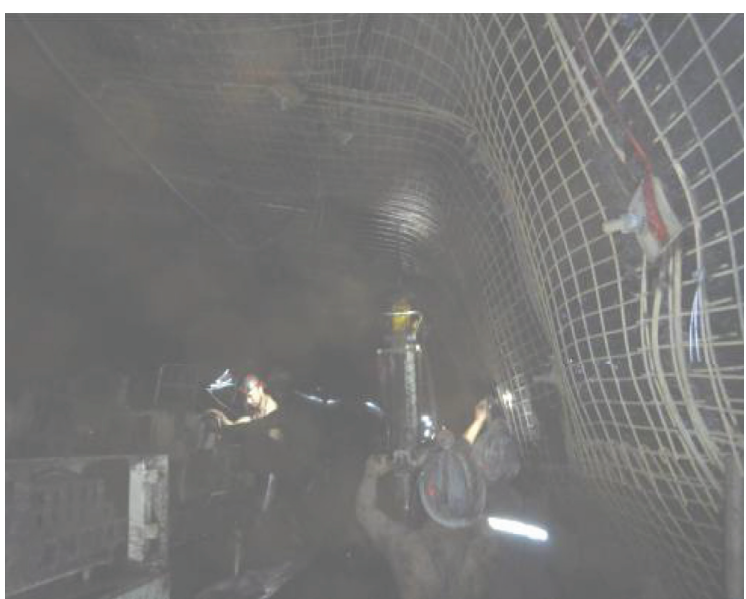

(b)

FIGURE 18: Site anchor bolt construction. (a) Hydraulic bolting rig in action. (b) Hand-held pneumatic bolt drill in action.

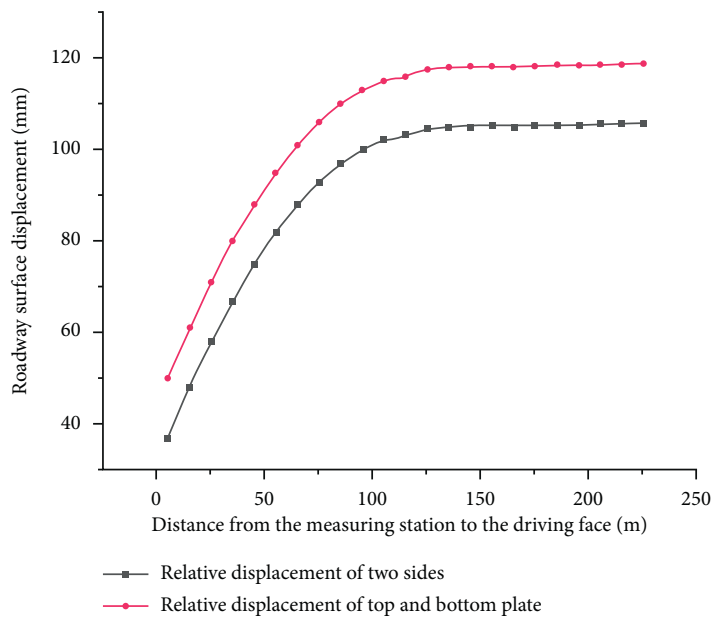

Figure 19: Convergence deformation curve of the roadway. 


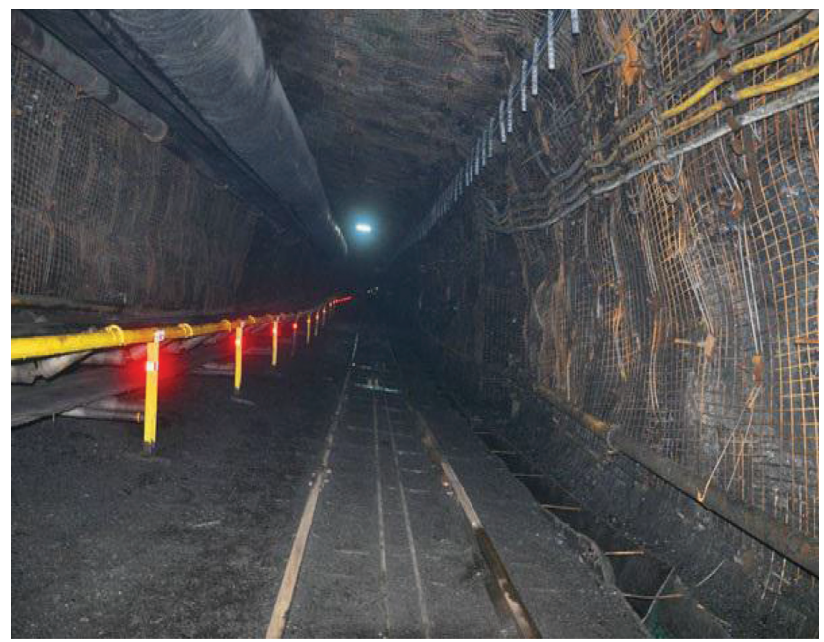

Figure 20: Stable section of the roadway.

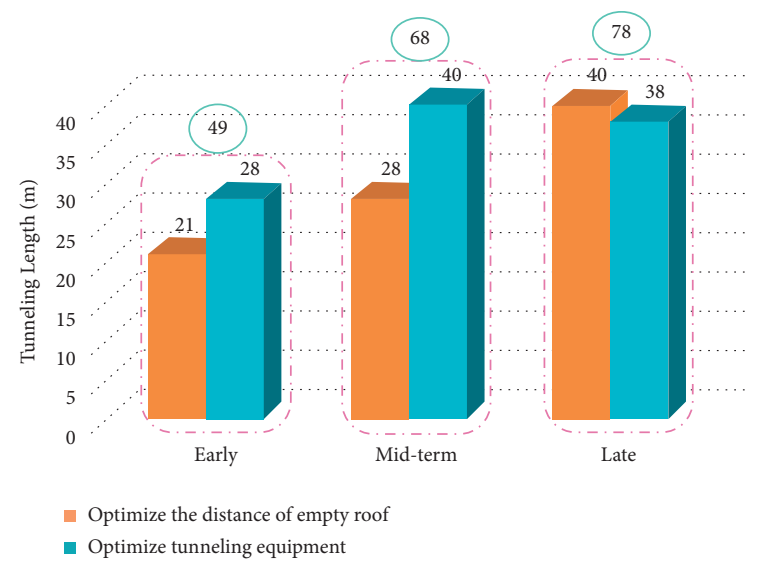

FIgURE 21: Roadway excavation effect.

\section{Conclusions}

(1) The expression of the deflection of the thin plate was calculated, and the influence of the single factor and the supporting force, the interaction of unsupported roof distance, and the load on the deflection of the thin plate were theoretically analyzed by the mechanical model of the thin plate of the roadway. The analysis results showed that the deflection deformation of the roadway roof under the single factor was more sensitive to the unsupported roof distance and the load interaction and less sensitive to the supporting force. The degree of influence of various factors on the deflection deformation of the thin plate in the unsupported roof area: unsupported roof distance and load interaction $>$ unsupported roof distance and supporting force interaction $>$ supporting force and load interaction.

(2) FLAC3D numerical simulation software was used to analyze the influence of different unsupported roof distances on the vertical stress distribution and displacement of the roadway roof. There was an obvious end effect in the vertical stress distribution of the roadway roof. The change in the unsupported roof distance as an effect of the vertical stress of the roadway roof is small. The position of the leading stress peak is the same $(3.0 \mathrm{~m}$ head-on in tunneling). With the increase in the unsupported roof distance, the roadway roof subsidence increases. When the unsupported roof distance is greater than $3.0 \mathrm{~m}$, the roof subsidence in the unsupported roof area is more obvious.

(3) The unsupported roof distance during roadway excavation is determined to be $2.0 \mathrm{~m}$ using theoretical analysis and numerical simulation calculations. The unsupported roof distance of $2 \mathrm{~m}$ is combined with the rapid excavation equipment and applied to the project site. The application shows that the roadway excavation speed is increased by $62.7 \%$, and the monthly footage reaches $506 \mathrm{~m}$.

\section{Data Availability}

The data used in the field measurement can be obtained from the corresponding author upon request.

\section{Conflicts of Interest}

The authors declare no conflicts of interest with respect to the research, authorship, and/or publication of this article.

\section{Acknowledgments}

The authors acknowledge the financial support provided by the National Natural Science Foundation of China (grant no. 51774010) for this work.

\section{References}

[1] C. Hu, "Design of reasonable heading distance between continuous miners in the boundary lane of no. 52 coal mine in Yujialiang Coal Mine," Coal, vol. 25, no. 6, pp. 18-19, 2016. 
[2] P. Ma, D. Qian, N. Zhang et al., "Application of bolter miner rapid excavation technology in deep underground roadway in inner Mongolia: a case study," Sustainability, vol. 12, no. 7, 2020.

[3] Z. Z. Xie, N. Zhang, D. Qian et al., "Rapid excavationand stability control of deep roadways for an underground coal minewith high production in Inner Mongolia," Sustainability, vol. 10, 2018.

[4] W. F. Yan and L. Shi, "The development status of coal roadway excavation technology and equipment in China," Coal Mine Machinery, vol. 39, no. 12, pp. 1-3, 2018.

[5] J. H. Wang, "China mechanized road header status and bolt support technology in mine seam roadway," Coal Science and Technology, vol. 31, no. 1, pp. 6-10, 2014.

[6] H. Wang, "Research and engineering practice on key technologies of intelligent quick excavation in coal mines," Journal of China Coal Society, vol. 47, no. 6, pp. 1-17, 2021.

[7] D. Bauer, "Summary of longwall and continuous miner section noise studies in underground coal mines," Mining Engineering, vol. 11, no. 2, pp. 56-58, 2006.

[8] K. Sen, "Continuous surface miner in mining limestone and coal in India - a comparative study," Journal of Mines, Metals and Fuels, vol. 5, no. 3, pp. 67-71, 2008.

[9] F. Y. Ye, "Development and trend of tunneling equipment in coal mines in my country," Coal Science and Technology, vol. 37, no. 4, pp. 61-64, 2009.

[10] H. P. Kang, J. H. Wang, and J. Lin, "Analysis of application examples of bolt support in coal mine roadway," Chinese Journal of Rock Mechanics and Engineering, vol. 29, no. 4, pp. 649-664, 2010.

[11] J. H. Wang, "New development of bolt support technology for coal roadways in my country," Journal of China Coal Society, vol. 2, pp. 113-118, 2007.

[12] N. Zhang, C. L. Han, and Z. Z. Xie, "The theory of continuous beam roof control and high-efficiency support technology for coal roadways," Journal of Mining and Strata Control Engineering, vol. 1, no. 2, pp. 48-55, 2019.

[13] R. Ma, "The roof failure mechanism and stability control of the roof in the empty roof area of rapid roadway excavation," China University of Mining and Technology, Xuzhou, China, Doctoral thesis, 2016.

[14] H. P. Kang, J. H. Wang, and J. Lin, "High prestress and strong support system and its application in deep roadway," Journal of China Coal Society, vol. 12, pp. 1233-1238, 2007.

[15] H. P. Kang, J. Lin, and Y. Z. Wu, "High-stress roadway strong bolt support technology and its application," Chinese Society of Rock Mechanics and Engineering, vol. 8, 2008.

[16] Z. F. Hu and G. H. Cao, "Support technology of high stress soft rock roadway," Mine pressure and roof management, vol. 14, no. 4, pp. 38-39, 2003.

[17] F. Xu, "Support design optimization and application of deep soft rock roadway," Coal mine support, vol. 32, no. 2, pp. 34-36, 2011.

[18] M. J. Fan, "Determination of reasonable empty roof distance in deep shaft large section coal roadway excavation," Coal Technology, vol. 35, no. 11, pp. 60-62, 2016.

[19] H. Z. Zhu, "Reasonable reservation of empty roof distance and construction optimization in rapid tunneling of coal roadway," Coal and chemical industry, vol. 42, no. 5, pp. 27-29+34, 2019.

[20] G. B. Li, Study on surrounding rock stability analysis and control technology of large section roadway in Ganhe coal mine, China University of mining and Technology, Beijing, China, 2013.
[21] X. W. Chu, "Deformation characteristics of head-on roof and determination method of reasonable space-top distance," Journal of Mining and Safety Engineering, vol. 37, no. 5, pp. 908-917, 2020.

[22] P. Q. Wu, "Research on the self-stabilization law of the empty roof and optimization of the construction plan for the rapid excavation of coal roadways," China University of Mining and Technology, vol. 34, no. 12, pp. 1585-1593, 2017.

[23] J. B. Bai, T. Q. Xiao, and L. Li, "Differential method and its application for determining the distance between empty and roof in roadway excavation," Journal of China Coal Society, vol. 36, no. 6, pp. 920-924, 2011.

[24] Z. Q. Zhang, Research on the spatio-temporal evolution characteristics and support mechanism of the stress shell of the surrounding rock of deep roadway, China University of Mining and Technology, Beijing, China, 2018.

[25] M. Cai and P. K. Kaiser, "In-situ rock spalling strength near excavation boundaries," Rock Mechanics and Rock Engineering, vol. 47, no. 2, pp. 659-675, 2014.

[26] H. Wu, B. Dai, L. Cheng, R. Lu, G. Zhao, and W. Liang, "Experimental study of dynamic mechanical response and energy dissipation of rock having a circular opening under impact loading," Mining, Metallurgy \& Exploration, vol. 38, no. 2, pp. 1111-1124, 2021a.

[27] S. Q. Niu, "Shearing instability mechanism and support method of roof layer of large-span roadway," Journal of China Coal Society, vol. 39, no. Supplement 2, pp. 325-331, 2014.

[28] B. Zya, L. C. Chang, A. Hz et al., "Mechanism of rock burst caused by fracture of key strata during irregular working face mining and its prevention methods," International Journal of Mining Science and Technology, vol. 29, no. 6, pp. 889-897, 2019.

[29] J. L. Wu, Elasticity, Higher Education Press, Beijing, China, 2001.

[30] H. Wu, D. Ma, A. J. S. Spearing et al., "Fracture phenomena and mechanisms of brittle rock with different numbers of openings under uniaxial loading," Geomechanics and Engineering, vol. 25, no. 6, pp. 481-493, 2021b.

[31] Z. Y. Xia, Z. Y. Tan, and J. F. Zhang, "Study on instability mechanism of extraction structure under undercut space based on thin plate theory in block caving method," Shock and Vibration, vol. 2021, Article ID 5548213, 11 pages, 2021. 